\title{
Haptoglobin genotype predicts development of coronary artery calcification in a prospective cohort of patients with type 1 diabetes
}

\author{
Melissa Simpson ${ }^{1}$, Janet K Snell-Bergeon ${ }^{1 *}$, Gregory L Kinney', Orit Lache², Rachel Miller-Lotan², Yefim Anbinder², \\ Marian J Rewers ${ }^{1}$ and Andrew P Levy ${ }^{2}$
}

\begin{abstract}
Background: Coronary artery disease has been linked with genotypes for haptoglobin ( $\mathrm{Hp}$ ) which modulates extracorpuscular hemoglobin. We hypothesized that the Hp genotype would predict progression of coronary artery calcification (CAC), a marker of subclinical atherosclerosis.

Methods: CAC was measured three times in six years among 436 subjects with type 1 diabetes and 526 control subjects participating in the Coronary Artery Calcification in Type 1 Diabetes (CACTI) study. Hp typing was performed on plasma samples by polyacrylamide gel electrophoresis.

Results: The Hp 2-2 genotype predicted development of significant CAC only in subjects with diabetes who were free of CAC at baseline (OR: 1.95, 95\% Cl: 1.07-3.56, $p=0.03$ ), compared to those without the Hp 2-2 genotype, controlling for age, sex, blood pressure and HDL-cholesterol. Hp 2 appeared to have an allele-dose effect on development of CAC. Hp genotype did not predict CAC progression in individuals without diabetes.

Conclusions: Hp genotype may aid prediction of accelerated coronary atherosclerosis in subjects with type 1 diabetes.
\end{abstract}

Keywords: Cardiovascular disease, type 1 diabetes mellitus, coronary artery calcium, hyperglycemia, genetics, Haptoglobin

\section{Background}

Coronary artery disease (CAD) is the leading cause of death in patients with type 1 diabetes and CAD mortality is $2-4$ higher among type 1 diabetes patients than in subjects without diabetes $[1,2]$. While hyperglycemia and conventional cardiovascular risk factors contribute to this increased risk, they do not account for all of the excess risk. Therefore additional markers are needed to predict which individuals with type 1 diabetes are at greatest risk for developing CAD [3]. Coronary artery calcium $(\mathrm{CAC})$ is a powerful marker of the coronary artery plaque burden [4]. Both the presence and progression of CAC have been shown to predict CAD events [5] and mortality [6].

\footnotetext{
* Correspondence: Janet.Snell-Bergeon@ucdenver.edu

${ }^{1}$ Barbara Davis Center for Childhood Diabetes, Aurora CO, USA

Full list of author information is available at the end of the article
}

Haptoglobin ( $\mathrm{Hp})$ is a protein whose primary function is to modulate the fate and toxicity of extracorpuscular hemoglobin [7]. The Hp protein is polymorphic with two classes of alleles, designated 1 and 2. In most populations of European ancestry, the prevalence of the $\mathrm{Hp}$ 1-1 genotype is < 20\%; Hp 2-1 and Hp 2-2 have approximately equal frequencies [8]. The protein products of the Hp 1 and Hp 2 alleles are structurally and functionally distinct. The Hp 1 protein mediates more rapid clearance of free hemoglobin and provides superior protection against hemoglobin-driven oxidation compared to the Hp 2 protein [7].

Studies in patients with type 2 diabetes have reported a 2-5 fold increased risk of myocardial infarction, stroke or CAD death in patients with the Hp 2-2 genotype, compared to those without the Hp 2-2 genotype [9-13]. In patients with type 1 diabetes, the Hp 2-2 genotype conferred an approximately 2 -fold increased risk of

\section{C) Biomed Central}


CAD, compared to Hp 1-1, with an intermediate risk found in Hp 2-1 individuals [9].

The association between the Hp genotype and CAC has not been previously examined. The purpose of this study was to investigate the Hp genotype as a predictor of CAC progression in adults with and without type 1 diabetes. Based on previous prospective studies of CAD, we hypothesized that the Hp 2-2 genotype would predict CAC progression in patients with type 1 diabetes, but not in those without diabetes.

\section{Methods}

\section{Study participants}

The Coronary Artery Calcification in Type 1 Diabetes (CACTI) study enrolled 1,416 individuals between 19 and 56 years of age, with no known history of CAD: 652 participants with type 1 diabetes and 764 control participants without diabetes. Twenty five people were excluded because they had a coronary event. Of those remaining, 172 individuals with type 1 diabetes and 216 controls have not completed the 6 year follow-up examination. Additional subjects were excluded because of missing plasma sample $(\mathrm{n}=28)$ or inability to determine the Hp genotype ( $n=13)$, leaving 436 subjects with diabetes and 526 controls in the analyses. The baseline CAD risk factors for the CACTI participants included in the analyses did not differ from those who were excluded, except for younger age of excluded controls. Participants with type 1 diabetes had long-standing disease (mean duration \pm SD: 23 years \pm 9 years) at baseline, were insulin dependent within 1 year of diagnosis, and were diagnosed prior to age 30 years or had positive antibodies or a clinical course consistent with type 1 diabetes. All study participants provided informed consent and the study protocol was approved by the Colorado Multiple Institutional Review Board.

\section{Coronary Artery Calcium Measurement}

At each examination, an ultrafast Imatron C-150XLP EBCT scanner (Imatron, San Francisco, CA) was used to obtain two sets of high resolution, noncontrast, contiguous 3-mm tomographic images acquired at 100-ms exposure. Scanning started from near the lower margin of bifurcation of the main pulmonary artery with the subject breathholding for $\sim 35-45 \mathrm{~s}$ and proceeded caudally. Calcified coronary artery areas were identified as those with a minimum density of 130 Hounsfeld units $(\mathrm{HU})$ and a minimum area of three pixels $(1.03 \mathrm{~mm} 2)$. A calcium score for each region was calculated by multiplying the area by the density score (1 for 130-199, 2 for 200-299, 3 for 300-399, and 4 for > $399 \mathrm{HU}$ ). A total CAC score in Agatston units (AU) was calculated by adding up scores for all slices separately for left main, left anterior descending, circumflex, and right coronary arteries [14]. The scanner was recalibrated every day with a phantom. Effective radiation dose for an EBCT sequence was $1.0 \mathrm{mSV}$ for men and $1.3 \mathrm{mSV}$ for women [15].

The presence of any CAC at baseline was defined as a CAC score $>0$ on either of the two scans. CAC progression was defined as a change in square root CAC volume $\geq 2.5$, as this difference was determined to be < $1 \%$ likely to be due to measurement error, based on the two scans that were completed within 5 minutes of one another [16]. The same CAC measurement protocol was followed at the baseline and 6 year follow up visit.

\section{Haptoglobin typing}

Hp typing was performed on stored plasma samples by polyacrylamide gel electrophoresis as previously described [17]. Briefly, $10 \mathrm{ul}$ of $\mathrm{Hb}$ enriched plasma was subjected to electrophoresis in a non-denaturing gel and the gel was subsequently immersed in solution containing a congener of benzidine with a precipitate forming in the gel corresponding to the location of $\mathrm{Hb}-\mathrm{Hp}$ complexes. The Hp type of the sample was determined by the banding pattern of the $\mathrm{Hp}-\mathrm{Hb}$ complexes with each of the three Hp types having a characteristic banding fingerprint. Previous work has established a 1:1 correspondence between this method and a PCR based method for Hp genotyping [17]. An unambiguous Hp type was obtained on $98.7 \%$ of all samples. For the purposes of quality and control and validation, we simultaneously measured the Hp type using an ELISA based assay $[7,18]$ with a greater than $97 \%$ agreement in the Hp type assigned by the two methods.

\section{Statistical analysis}

We used two analytic approaches to examine the association between CAC and Hp polymorphism: linear regression and logistic regression. For both analyses, we considered the following baseline CAD risk factors as covariates: sex, age, diastolic blood pressure $(\mathrm{mmHg})$, systolic blood pressure $(\mathrm{mmHg})$, body mass index $(\mathrm{Kg} /$ $\mathrm{m}^{2}$ ) (BMI), low-density lipoproteins (LDL), high-density lipoproteins (HDL), triglycerides, hemoglobin A1c (\%), self-reported history of ever smoking, and baseline square root transform of the CAC volume among those with CAC present at the baseline examination. We used backwards selection to build the most parsimonious model; this selection process entails removing the covariate that has the largest p-value given the other covariates in the model until all covariates included have a $\mathrm{p}$ value $<0.05$. Any covariate whose $\mathrm{p}$-value was not $<$ 0.05 in the multivariate model was not included in the final adjusted model. Assessment of baseline CAD risk factors have been previously described [15]. The outcome in linear regression analyses was the change in 
square root transformed CAC volume over the 6 year follow up period. For logistic regression analyses, CAC progression was defined as a change in the square root transformed CAC volume $\geq 2.5$ over the 6 year period of follow-up, which corresponds to a change in CAC volume from 0 to $\geq 6.25$ among participants initially free from CAC. This cut off was chosen because it is the point at which the change in CAC is significant enough that it can not be attributed to interscan variability [16]. All analyses were performed using SAS for Windows version 9.2 (SAS Institute Inc., Cary, NC, USA).

\section{Results}

Table 1 describes the demographic characteristics of the study population stratified by diabetes status and CAC progression over a mean time between the baseline and the follow up visit of 6.5 years $( \pm 0.6$, minimum: 4 , maximum: 9). In the univariate comparison, the frequency of the Hp 2-2 polymorphism did not differ by CAC progression ( $\mathrm{p}=0.13$ in participants with type 1 diabetes and $\mathrm{p}=0.17$ in those without diabetes).

\section{Linear regression of the change in square root transform CAC volume}

The Hp 2-2 polymorphism predicted change in CAC volume only in subjects with type 1 diabetes who were free of CAC at the baseline visit (Table 2, bold type). The findings were similar with adjustment for age and sex only $(\mathrm{p}=0.03)$ and when additionally adjusting for systolic blood pressure and HDL-cholesterol $(\mathrm{p}=0.05)$. Hp polymorphism was not associated with change in CAC volume in subjects with type 1 diabetes with CAC present at baseline or in subjects without diabetes, regardless of $\mathrm{CAC}$ extent at baseline.

\section{Logistic regression of 6 year CAC progression}

Similar to the above findings, the Hp 2-2 polymorphism predicted development of CAC (a change in CAC volume from 0 to $\geq 6.25$ or in square root transformed CAC volume from 0 to $\geq 2.5$ ) only in subjects with type 1 diabetes free of $\mathrm{CAC}$ at the baseline examination when adjusting for age and sex (OR: 2.03, 95\% CI: 1.13$3.65, \mathrm{p}=0.02)$, and when additionally adjusting for systolic blood pressure and HDL cholesterol (OR: 1.95, 95\% CI: $1.07-3.56, \mathrm{p}=0.03)$ compared to those without the Hp 2-2 polymorphism (Table 3). Hp polymorphism did not predict CAC progression in individuals without diabetes.

Among patients with diabetes free of CAC at baseline, Hp 2 appeared to have an allele-dose effect on development of CAC: Hp 2-1 OR: 1.72 (1.09-2.71) and Hp 2-2 OR: 2.94 (1.87-4.65), compared to Hp 1-1 and adjusting for age and sex (Figure 1).

\section{Discussion}

The major finding of this study is that the Hp 2-2 polymorphism, and to a lesser extent the 2-1 polymorphism,

Table 1 Baseline characteristics in study subjects with 6 year progression data and Hp genotype data by diabetes status

\begin{tabular}{|c|c|c|c|c|c|c|}
\hline \multirow[t]{3}{*}{ Characteristic } & \multicolumn{2}{|c|}{ Study subjects with type 1 diabetes } & \multicolumn{4}{|c|}{ Control subjects without type 1 diabetes } \\
\hline & $\begin{array}{c}6 \text { Year CAC Progression } \\
\geq 2.5\end{array}$ & $\begin{array}{c}6 \text { Year CAC Progression } \\
<2.5\end{array}$ & & $\begin{array}{c}6 \text { Year CAC Progression } \\
\geq 2.5\end{array}$ & $\begin{array}{c}6 \text { Year CAC Progression } \\
<2.5\end{array}$ & \\
\hline & $n=178$ & $n=258$ & & $n=150$ & $n=376$ & \\
\hline CAC present at baseline visit & $113(63)$ & $37(14)$ & * & $86(57)$ & $51(14)$ & \\
\hline Haptoglobin genotype 2-2 & $76(43)$ & $89(35)$ & & $46(31)$ & 139(37) & \\
\hline $\begin{array}{l}\text { Mean } 6 \text { year change in CAC } \\
\text { volume }\end{array}$ & $7.4 \pm 4.4$ & $0.4 \pm 0.8$ & * & $5.8 \pm 3.1$ & $0.3 \pm 0.7$ & . \\
\hline Female & $78(44)$ & $160(62)$ & * & $41(27)$ & 223(59) & 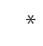 \\
\hline Mean age (years) & $40.1 \pm(8.1)$ & $34.0 \pm 8.2)$ & * & $45.2 \pm 7.3)$ & $39.0 \pm 8.5$ & * \\
\hline $\begin{array}{l}\text { Mean diastolic blood pressure } \\
(\mathrm{mmHg})\end{array}$ & $78.0 \pm 9.0$ & $76.3 \pm 8.4$ & * & $83.2 \pm 8.9$ & $77.2 \pm 7.6$ & 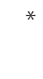 \\
\hline $\begin{array}{l}\text { Mean systolic blood pressure } \\
(\mathrm{mmHg})\end{array}$ & $120.2 \pm 13.6$ & $113.9 \pm 12.1$ & * & $120.4 \pm 12.7$ & $111.6 \pm 11.1$ & 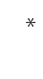 \\
\hline Mean body mass index $\left(\mathrm{kg} / \mathrm{m}^{2}\right)$ & $26.7 \pm 4.3$ & $25.6 \pm 4.0$ & * & $28.2 \pm 4.8$ & $25.3 \pm 4.4$ & \\
\hline Mean LDL cholesterol (mmol/l) & $2.7 \pm 0.73$ & $2.5 \pm 0.7$ & * & $3.1 \pm 0.8$ & $3.0 \pm 0.8$ & . \\
\hline Mean HDL cholesterol (mmol/l) & $1.4 \pm 0.4$ & $1.5 \pm 0.4$ & * & $1.2 \pm 0.3$ & $1.4 \pm 0.4$ & . \\
\hline Mean triglycerides $(\mathrm{mmol} / \mathrm{l})$ & $1.1 \pm 0.01$ & $1.0 \pm 0.5$ & * & $1.8 \pm 1.2$ & $1.3 \pm 0.7$ & 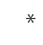 \\
\hline Mean HbA1c (\%) & $8.0 \pm 1.2$ & $7.8 \pm 1.2$ & & $5.6 \pm 0.4$ & $5.4 \pm 0.4$ & \\
\hline Ever smoker & $48(27)$ & $39(15)$ & * & $27(18)$ & $86(23)$ & \\
\hline
\end{tabular}

* p-value less than 0.05 comparing CAC progression in individuals with type 1 diabetes and control subjects separately Data are presented as mean $\pm \mathrm{sd}$ or as $\mathrm{n}(\%)$ 
Table 2 Adjusted $\beta$ estimates from linear regression analyzing the association between Hp genotype and square root transformed CAC volume, stratified by the presence of CAC at baseline

\begin{tabular}{|c|c|c|c|c|c|}
\hline \multirow[b]{2}{*}{ Characteristic } & & \multicolumn{2}{|c|}{$\begin{array}{l}\text { Adjusting for age } \\
\text { and sex only }\end{array}$} & \multicolumn{2}{|c|}{$\begin{array}{c}\text { Including } \\
\text { covariates from } \\
\text { backwards } \\
\text { selection model* }\end{array}$} \\
\hline & & $\begin{array}{c}\beta \\
\text { estimate }\end{array}$ & $p$-value & $\begin{array}{c}\beta \\
\text { estimate }\end{array}$ & $p$-value \\
\hline $\begin{array}{l}\text { Hp genotype * diabetes interaction* }{ }^{*} \text { presence of CAC at } \\
\text { baseline interaction }\end{array}$ & & N/A & 0.001 & N/A & 0.001 \\
\hline \multirow[t]{2}{*}{ CAC not present at the baseline visit } & $\begin{array}{l}\text { Hp 2-2 vs. 2-1/1-1 in patients with } \\
\text { diabetes }\end{array}$ & 0.82 & 0.03 & 0.74 & 0.05 \\
\hline & $\begin{array}{l}\text { Hp } 2-2 \text { vs. } 2-1 / 1-1 \text { in controls without } \\
\text { diabetes }\end{array}$ & 0.67 & 0.2 & 0.83 & 0.11 \\
\hline \multirow[t]{2}{*}{ CAC present at the baseline visit } & $\begin{array}{l}\text { Hp } 2-2 \text { vs. } 2-1 / 1-1 \text { in patients with } \\
\text { diabetes }\end{array}$ & -0.34 & 0.3 & -0.31 & 0.33 \\
\hline & $\begin{array}{l}\text { Hp 2-2 vs. 2-1/1-1 in controls without } \\
\text { diabetes }\end{array}$ & -2.02 & 0.52 & 0.24 & 0.7 \\
\hline Age & & 0.11 & $<0.0001$ & 0.1 & $<0.0001$ \\
\hline Female vs. male & & -1.17 & $<0.0001$ & 0.22 & 0.001 \\
\hline Systolic blood pressure & & \multicolumn{2}{|c|}{ N/A } & 0.01 & $<0.0001$ \\
\hline HDL cholesterol & & \multicolumn{2}{|c|}{ N/A } & 0.01 & 0.003 \\
\hline
\end{tabular}

* Adjusting for age, sex, systolic blood pressure and HDL-cholesterol

predicts development of coronary artery calcification in people with type 1 diabetes over a period of 6 years. The findings were internally consistent, using two definitions of CAC progression in linear and logistic regression analyses. Our finding that $\mathrm{Hp}$ polymorphisms predict new CAC only in patients with diabetes is consistent with previous reports from studies using clinical CAD endpoints $[9,10,12,13]$.

Consistent with our findings, the Pittsburgh Epidemiology of Diabetes Complications Study of patients with type 1 diabetes, has shown an allele-dose effect of the Hp 2 allele on the risk of incident CAD [9]. Thus, among individuals with type 1 diabetes, the $\mathrm{Hp} 2$ allele plays an important role in subclinical coronary atherosclerosis and progression to clinical events.

The apparent lack of effect of Hp genotype on progression of CAC in patients already CAC positive is puzzling and requires further evaluation. While we adjusted for baseline extent of CAC in the models among patients already CAC positive, it is possible that

Table 3 Adjusted odds ratios for the association between CAC progression and Hp genotype, stratified by presence of CAC at baseline

\begin{tabular}{|c|c|c|c|c|c|c|c|}
\hline \multirow[b]{2}{*}{ Characteristic } & & \multicolumn{3}{|c|}{$\begin{array}{l}\text { Adjusting for age and } \\
\text { sex only }\end{array}$} & \multicolumn{3}{|c|}{$\begin{array}{l}\text { Including covariates } \\
\text { from backwards } \\
\text { selection model* }\end{array}$} \\
\hline & & OR & $95 \% \mathrm{Cl}$ & $p$-value & OR & $95 \% \mathrm{Cl}$ & $p$-value \\
\hline $\begin{array}{l}\mathrm{Hp} \text { genotype * diabetes interaction* }{ }^{*} \text { presence of CAC at } \\
\text { baseline interaction }\end{array}$ & & & N/A & 0.03 & & N/A & 0.09 \\
\hline \multirow[t]{2}{*}{ CAC not present at the baseline visit } & $\begin{array}{l}\text { Hp } 2-2 \text { vs. } 2-1 / 1-1 \text { in patients with } \\
\text { diabetes }\end{array}$ & 2.03 & $1.13-3.65$ & 0.02 & 1.95 & $1.07-3.56$ & 0.03 \\
\hline & $\begin{array}{l}\text { Hp } 2-2 \text { vs. } 2-1 / 1-1 \text { in controls } \\
\text { without diabetes }\end{array}$ & 0.83 & $0.37-1.84$ & 0.65 & 0.69 & $0.38-1.27$ & 0.94 \\
\hline \multirow[t]{2}{*}{ CAC present at the baseline visit } & $\begin{array}{l}\text { Hp } 2-2 \text { vs. } 2-1 / 1-1 \text { in patients with } \\
\text { diabetes }\end{array}$ & 0.68 & $0.37-1.24$ & 0.21 & 0.80 & $0.33-1.93$ & 0.22 \\
\hline & $\begin{array}{l}\text { Hp } 2-2 \text { vs. } 2-1 / 1-1 \text { in controls } \\
\text { without diabetes }\end{array}$ & 1.33 & $0.94-3.28$ & 0.07 & 1.17 & $0.49-2.81$ & 0.29 \\
\hline Age & & 1.08 & $1.05-1.10$ & $<0.0001$ & 1.08 & $1.05-1.10$ & 0.009 \\
\hline Female vs. male & & 0.43 & $0.31-0.60$ & $<0.0001$ & 0.65 & $0.45-0.94$ & $<0.0001$ \\
\hline Systolic blood pressure & & & N/A & & 1.03 & $1.02-1.05$ & $<0.0001$ \\
\hline HDL cholesterol & & & N/A & & 0.97 & 0.96-0.99 & 0.0001 \\
\hline Square root $C A C$ volume at baseline & & & N/A & & 1.25 & $1.13-1.38$ & $<0.0001$ \\
\hline
\end{tabular}

* Adjusting for age, sex, systolic blood pressure and HDL-cholesterol 


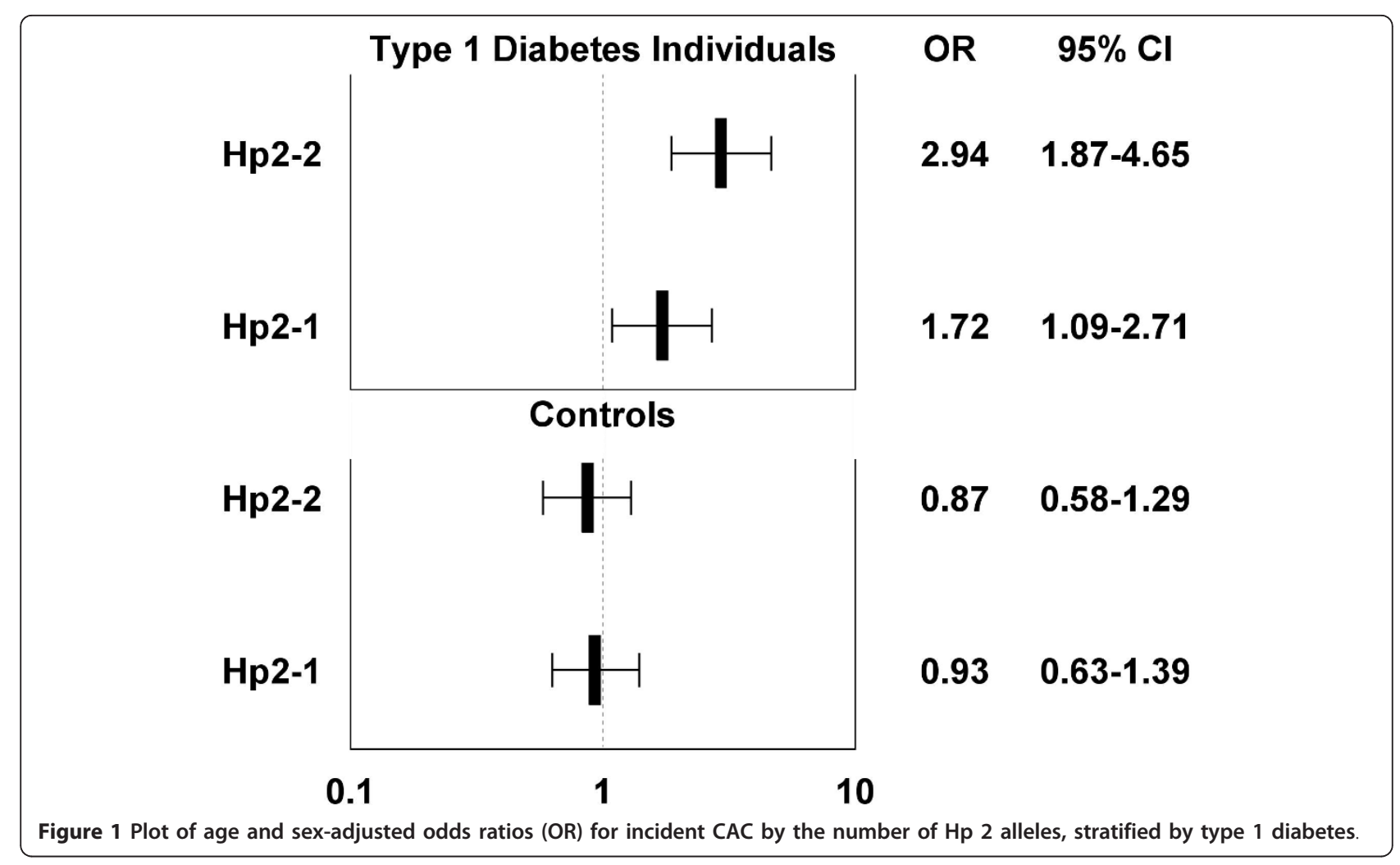

residual confounding by the level of baseline CAC remains. In addition, incident $\mathrm{CAC}$ and $\mathrm{CAC}$ progression may reflect different biological processes and prognoses. The development of CAC is a process which increases risk for future acute coronary events, [5] and $\mathrm{CAC}$ progression is a powerful predictor of mortality even among persons who already have CAC present; [6] However, calcification of a plaque itself does not promote plaque rupture [19].

No other cohorts with data about incident CAC in individuals with type 1 diabetes exist in which to validate our findings. However, the results of this study validate those from studies of clinical endpoints by using the subclinical outcome of $\mathrm{CAC}$, thereby demonstrating that the Hp genotype is a robust biomarker for atherosclerosis in individuals with type 1 diabetes.

The different effect of $\mathrm{Hp} 1$ and $\mathrm{Hp} 2$ proteins on cardiovascular risk in patients with diabetes potentially derives from several mechanisms. First, Hp regulates the fate and toxicity of extracorpuscular hemoglobin [7]. Upon binding to hemoglobin, the Hp 1 protein is superior to the Hp 2 protein in protecting against oxidation mediated by $\mathrm{Hb}$ derived iron [20] and HDL dysfunction, [21] particularly in the setting of diabetes. In addition, recent evidence suggests a more diverse physiologic role for Hp. Delanghe et al. summarized the evidence that Hp polymorphisms play a role in the regulation of both
T- and B- cells, particularly with respect to the immune response to atherosclerosis and $\mathrm{Hb}$ driven lipid oxidation [22]. Other recent publications presented data suggesting that $\mathrm{Hp}$ (both genotype and circulating concentrations) has a role in remodeling the myocardium and, therefore, prognosis after myocardial infarction (MI) [23,24]. To help elucidate these mechanisms, future observational research may want to study the association between Hp concentration and CAC development as well as the interaction between the immunologic profile of people with type 1 diabetes and $\mathrm{Hp}$.

\section{Conclusions}

This study adds to the literature concerning the increased risk for CAD among patients with type 1 diabetes who have the $\mathrm{Hp} 2$ allele and extends that research by studying progression of subclinical atherosclerosis rather than clinical CAD events. In so doing, this study has identified a sub-group of people towards whom primary prevention efforts may be directed. For example, the ICARE study found that vitamin $\mathrm{E}$ is useful in prevention of clinical cardiovascular events among individuals with type 2 diabetes and the Hp 2-2 polymorphism $[25,26]$. Therefore, it may be useful to initiate a similar clinical trial targeted at $\mathrm{Hp}$ 2-2 individuals with type 1 diabetes and no CAC. Furthermore, utilization of incident CAC, as opposed to hard clinical events, 
would allow for a markedly less costly trial design assessing the efficacy of such a pharmacogenomic algorithm.

\section{Abbreviations}

(AU): Agatston units; (CAC): coronary artery calcium; (CAD): coronary artery disease; (Hp): Haptoglobin; $(H u)$ : Hounsfield units.

\section{Acknowledgements}

The study was performed at the Barbara Davis Center for Childhood Diabetes in Denver, CO, and at Colorado Heart Imaging Center in Denver, CO. Support was provided by the NIH National Heart, Lung and Blood Institute grants R01 HL61753 and R01 HL079611, American Diabetes Association post-doctoral fellowship 7-09-CVD-06 (MS), American Diabetes Association Junior Faculty Award 1-10-JF-50 (JSB) and Diabetes Endocrinology Research Center Clinical Investigation Core P30 DK57516. The study was performed at the Clinical Translational Research Center at the University of Colorado Denver supported by the NIH M01 RR000051. This study was supported by grants from the BSF, JDRF and $\mathrm{NIH}(\mathrm{NIH}$ R01DK085226) to APL.

\section{Author details}

${ }^{1}$ Barbara Davis Center for Childhood Diabetes, Aurora CO, USA. ${ }^{2}$ Technion Faculty of Medicine, Technion Israel Institute of Technology, Haifa, Israel.

\section{Authors' contributions}

MS analyzed the data that are reported here and wrote this manuscript. JSB and GK collected patient data, assisted in the analysis and reporting of the data herein, and made editorial contributions to the manuscript. MR designed and supervised the CACTI study, and made extensive scientific and editorial contributions to this manuscript. OL, RML, and YA genotyped participant samples for Haptoglobin and made editorial contributions to the manuscript. AL developed the method for Haptoglobin genotyping, assisted in data analysis, and made extensive scientific and editorial contributions to this manuscript. All authors have read and approved the final manuscript.

\section{Competing interests}

The authors declare that they have no competing interests.

Received: 4 October 2011 Accepted: 20 November 2011 Published: 20 November 2011

\section{References}

1. Krolewski AS, Kosinski EJ, Warram JH, Leland OS, Busick EJ, Asmal AC, Rand LI, Christlieb AR, Bradley RF, Kahn CR: Magnitude and determinants of coronary artery disease in juvenile-onset, insulin-dependent diabetes mellitus. The American journal of cardiology 1987, 59:750-755.

2. Laing SP, Swerdlow AJ, Slater SD, Burden AC, Morris A, Waugh NR, Gatling W, Bingley PJ, Patterson CC: Mortality from heart disease in a cohort of 23,000 patients with insulin-treated diabetes. Diabetologid 2003, 46:760-765.

3. Farbstein D, Levy AP: The genetics of vascular complications in diabetes mellitus. Cardiology clinics 2010, 28:477-496.

4. Agatston AS, Janowitz WR, Kaplan G, Gasso J, Hildner F, Viamonte M Jr: Ultrafast computed tomography-detected coronary calcium reflects the angiographic extent of coronary arterial atherosclerosis. The American journal of cardiology 1994, 74:1272-1274.

5. Raggi P, Cooil B, Shaw L, Aboulhson J, Takasu J, Budoff M, Callister TQ: Progression of coronary calcium on serial electron beam tomographic scanning is greater in patients with future myocardial infarction. The American journal of cardiology 2003, 92:827-829.

6. Budoff MJ, Hokanson JE, Nasir K, Shaw LJ, Kinney GL, Chow D, Demoss D,

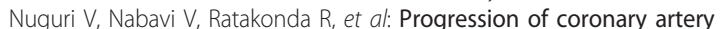
calcium predicts all-cause mortality. JACC Cardiovascular imaging 2010, 3:1229-1236.

7. Levy AP, Asleh R, Blum S, Levy NS, Miller-Lotan R, Kalet-Litman S, Anbinder Y, Lache O, Nakhoul FM, Asaf R, et al: Haptoglobin: basic and clinical aspects. Antioxidants \& redox signaling 2010, 12:293-304.
8. Bowman $\mathrm{BH}$, Kurosky A: Haptoglobin: the evolutionary product of duplication, unequal crossing over, and point mutation. Advances in human genetics 1982, 12:189-261, 453-184.

9. Costacou T, Ferrell RE, Orchard TJ: Haptoglobin genotype: a determinant of cardiovascular complication risk in type 1 diabetes. Diabetes 2008, 57:1702-1706.

10. Levy AP, Hochberg I, Jablonski K, Resnick HE, Lee ET, Best L, Howard BV Haptoglobin phenotype is an independent risk factor for cardiovascular disease in individuals with diabetes: The Strong Heart Study. Journal of the American College of Cardiology 2002, 40:1984-1990.

11. Levy AP, Roguin A, Hochberg I, Herer P, Marsh S, Nakhoul FM, Skorecki K: Haptoglobin phenotype and vascular complications in patients with diabetes. The New England journal of medicine 2000, 343:969-970.

12. Roguin A, Koch W, Kastrati A, Aronson D, Schomig A, Levy AP: Haptoglobin genotype is predictive of major adverse cardiac events in the 1-year period after percutaneous transluminal coronary angioplasty in individuals with diabetes. Diabetes care 2003, 26:2628-2631.

13. Suleiman M, Aronson D, Asleh R, Kapeliovich MR, Roguin A, Meisel SR, Shochat M, Sulieman A, Reisner SA, Markiewicz W, et al: Haptoglobin polymorphism predicts 30-day mortality and heart failure in patients with diabetes and acute myocardial infarction. Diabetes 2005, 54:2802-2806.

14. Agatston AS, Janowitz WR, Hildner FJ, Zusmer NR, Viamonte M Jr, Detrano R: Quantification of coronary artery calcium using ultrafast computed tomography. Journal of the American College of Cardiology 1990, 15:827-832.

15. Dabelea D, Kinney G, Snell-Bergeon JK, Hokanson JE, Eckel RH, Ehrlich J, Garg S, Hamman RF, Rewers M: Effect of type 1 diabetes on the gender difference in coronary artery calcification: a role for insulin resistance? The Coronary Artery Calcification in Type 1 Diabetes (CACTI) Study. Diabetes 2003, 52:2833-2839.

16. Hokanson JE, MacKenzie T, Kinney G, Snell-Bergeon JK, Dabelea D, Ehrlich J, Eckel $\mathrm{RH}$, Rewers M: Evaluating changes in coronary artery calcium: an analytic method that accounts for interscan variability. AJR American journal of roentgenology 2004, 182:1327-1332.

17. Koch W, Latz W, Eichinger M, Roguin A, Levy AP, Schomig A, Kastrati A: Genotyping of the common haptoglobin $\mathrm{Hp} 1 / 2$ polymorphism based on PCR. Clinical chemistry 2002, 48:1377-1382.

18. Victor J CW, Chen JS, Levy N, Miller-Lotan R, Levy AP, Blum S, Orchard TJ, Evans RW, Costacou T, Hauth BA: Clinical Results of a Rapid Screening Assay for Haptoglobin 2-2: A Cardiovascular Disease Risk Marker (abstract). American Diabetes Association 69th Scientific Sessions; New Orleans LA. Diabetes 2009, 652-P.

19. Virmani R, Burke AP, Farb A, Kolodgie FD: Pathology of the vulnerable plaque. Journal of the American College of Cardiology 2006, 47:C13-18.

20. Asleh R, Guetta J, Kalet-Litman S, Miller-Lotan R, Levy AP: Haptoglobin genotype- and diabetes-dependent differences in iron-mediated oxidative stress in vitro and in vivo. Circulation research 2005, 96:435-441.

21. Asleh R, Blum S, Kalet-Litman S, Alshiek J, Miller-Lotan R, Asaf R, Rock W, Aviram M, Milman U, Shapira C, et al: Correction of HDL dysfunction in individuals with diabetes and the haptoglobin 2-2 genotype. Diabetes 2008, 57:2794-2800.

22. Delanghe JR, Langlois MR, De Buyzere ML: Haptoglobin polymorphism: a key factor in the proatherogenic role of B cells? Atherosclerosis 2011, 217:80-82

23. Haas B, Serchi T, Wagner DR, Gilson G, Planchon S, Renaut J, Hoffmann L, Bohn T, Devaux Y: Proteomic analysis of plasma samples from patients with acute myocardial infarction identifies haptoglobin as a potential prognostic biomarker. Journal of proteomics 2011.

24. Asaf R, Blum S, Roguin A, Kalet-Litman S, Kheir J, Frisch A, Miller-Lotan R, Levy AP: Haptoglobin genotype is a determinant of survival and cardiac remodeling after myocardial infarction in diabetic mice. Cardiovascular diabetology 2009, 8:29.

25. Blum S, Vardi M, Brown JB, Russell A, Milman U, Shapira C, Levy NS, MillerLotan R, Asleh R, Levy AP: Vitamin E reduces cardiovascular disease in individuals with diabetes mellitus and the haptoglobin 2-2 genotype. Pharmacogenomics 2010, 11:675-684.

26. Milman U, Blum S, Shapira C, Aronson D, Miller-Lotan R, Anbinder $Y$ Alshiek J, Bennett L, Kostenko M, Landau M, et al: Vitamin E supplementation reduces cardiovascular events in a subgroup of middle-aged individuals with both type 2 diabetes mellitus and the 
haptoglobin 2-2 genotype: a prospective double-blinded clinical trial. Arteriosclerosis, thrombosis, and vascular biology 2008, 28:341-347.

doi:10.1186/1475-2840-10-99

Cite this article as: Simpson et al: Haptoglobin genotype predicts

development of coronary artery calcification in a prospective cohort of patients with type 1 diabetes. Cardiovascular Diabetology 2011 10:99.

Submit your next manuscript to BioMed Central and take full advantage of:

- Convenient online submission

- Thorough peer review

- No space constraints or color figure charges

- Immediate publication on acceptance

- Inclusion in PubMed, CAS, Scopus and Google Scholar

- Research which is freely available for redistribution

Submit your manuscript at www.biomedcentral.com/submit 